\title{
Legislative Update: December 2000
}

\author{
Allison Weber Shuren, NP, JD*, and Stacy Harbison, BS**
}

\section{ADDITION OF PAIN MANAGEMENT CODES TO ASC PROCEDURE LIST}

On November 17, the Health Care Financing Administration (HCFA) issued a Program Memorandum providing replacement codes to the Ambulatory Surgical Center (ASC) list of approved services for the nine (9) pain management codes that were replaced by CPT 2000. In the Program Memorandum HCFA stated, “The matter of these codes has been brought to our attention and, upon careful review by our medical staff, we have determined that these codes did indeed replace services that were previously covered by ASC listed procedures...”

This change was brought about due to the tireless efforts of ASIPP, including the leadership of Dr. Manchikanti and the visits of ASIPP members to their Congressional representatives during the September 5, Capitol Hill Day. Upon the request of ASIPP, some Congressional offices contacted HCFA by letter urging the addition of pain management codes. Those offices are as follows: Senator Mitch McConnell (R-KY), Senator John Rockefeller (DWV), Congressman Frank Pallone (D-NJ), Congressman Ed Whitfield (R-KY), Congresswoman Anne Northup (R$\mathrm{KY}$ ), Congressman Ken Lucas (D-KY), and Congressman Ron Lewis (R-KY). ASIPP has sent follow-up thank you letters to these Members expressing appreciation for their involvement in this successful event.

\section{MEDICARE PHYSICIAN FEE SCHEDULE}

The Health Care Financing Administration released the 2001 Physician Fee Schedule final rule November 1st. Under the rule, effective January 1, 2001 the annual con-

From Arent Fox Klintner Plotkin \& Khan, PLLC, Washington, D.C. *Ms. Shuren is an attorney at Arent Fox and Counsel for the American Society of Interventional Pain Physicians. ** Ms.Harbison is a Government Relations Assistant. Address correspondence: Allison Weber Shuren, Esq., 1050 Connecticut Avenue NW, Washington, D.C. 20036 version factor will be $\$ 38.2581$, a 5.1\% percent update from the 2000 schedule. The 2001 schedule also represents year three of the four year transition from the form charge-based fee schedule to the resource-based fee schedule required by the Balanced Budget Act of 1997.

In part due to the tireless advocacy efforts of the Association of Interventional Pain Physicians, payment under the fee schedule for many of the procedures most frequently performed by pain management specialists in the physician office setting has been increased some 15 to 20 percent. Among the most critical issues ASIPP pushed with HCFA were reimbursement for lumbar facet radiofrequency, diskography procedures, and radiologic procedures in interventional pain management which faced substancialcuts in reimbursement. These cuts were eliminated with raises for the same procedures, due to lobbying of ASIPP. Payments for the procedures performed in ASC and hospitals rose but to a lesser extent. The complete rule may be accessed on the HCFA internet site at http://www.hcfa.gov. Concessions achieved due to ASIPP efforts may be viewed at http://www.asipp.org.

\section{MEDICARE GIVEBACK BILL}

The House of Representatives passed a Medicare bill and the Pain Relief Promotion Act. This bill would provide more than $\$ 30$ billion in Medicare and Medicaid funding modifications. Hospitals and health maintenance organizations are expected to receive around \$11 billion each in restorations, while nursing homes are expected to receive an additional $\$ 1.5$ billion.

Importantly, the bill would require MedPAC to conduct a study on the barriers to coverage and payment for outpatient interventional pain procedures under the Medicare program. It also provides for a delay in the implementation of the ASC prospective payment system until 2002 and an extension of the phase-in of the system over four years. 